\title{
Structural validity of the Brazilian version of the Western Ontario and McMaster Universities Osteoarthritis Index among patients with knee osteoarthritis
}

\author{
Cheila de Sousa Bacelar Ferreira', Almir Vieira Dibai-Filho", Davi Oliveira da Silva Almeida"', Daniela Bassi-Dibai" , Felipe Souza \\ Barreto" , Adriano Rodrigues de Oliveirav", Cid André Fidelis-de-Paula-Gomes"vil
}

Postgraduate Program on Rehabilitation Sciences, Universidade Nove de Julho (UNINOVE), São Paulo (SP), Brazil

\author{
'PT. Master's Student, Postgraduate Program on \\ Rehabilitation Sciences, Universidade Nove de \\ Julho (UNINOVE), São Paulo (SP), Brazil. \\ (D) orcid.org/0000-0001-9031-5396 \\ "PhD. Professor, Postgraduate Program on \\ Physical Education, Universidade Federal do \\ Maranhão (UFMA), São Luís (MA), Brazil. \\ (D) orcid.org/0000-0001-5403-8248 \\ '"Physical Education Teacher and Master's \\ Student, Postgraduate Program on \\ Rehabilitation Sciences, Universidade Nove de \\ Julho (UNINOVE), São Paulo (SP), Brazil. \\ (D) orcid.org/0000-0001-9153-6123
}

"vhD. Professor, Postgraduate Program on Programs Management and Healthcare Services, Universidade Ceuma, São Luís (MA), Brazil. (D) orcid.org/0000-0002-6140-0177

vPT. Master's Student, Postgraduate Program on Physical Education, Universidade Federal do Maranhão (UFMA), São Luís (MA), Brazil.

(D) orcid.org/0000-0002-8998-4776

viPhD. Professor, Department of Physical Therapy, Universidade Nove de Julho (UNINOVE), São Paulo (SP), Brazil.

(D) orcid.org/0000-0002-7848-7686

VIIPhD. Professor, Postgraduate Program on Rehabilitation Sciences, Universidade Nove de Julho (UNINOVE), São Paulo (SP), Brazil. (D) orcid.org/0000-0001-6627-7537

KEY WORDS (MeSH terms):

Reproducibility of results.

Surveys and questionnaires.

Pain.

Rheumatology.

\section{AUTHORS' KEY WORDS:}

Joint degeneration

Exploratory factor analysis.

Confirmatory factor analysis.

WOMAC.
BACKGROUND: The original structure of the Western Ontario and McMaster Universities Osteoarthritis Index (WOMAC) has been contested in several languages.

OBJECTIVE: To assess the structural validity of the Brazilian version of WOMAC among patients with knee osteoarthritis.

DESIGN AND SETTING: Structural validity study conducted at physiotherapy clinics and primary healthcare units.

METHODS: The study included males and females aged 40 to 80 years who were all native Brazilian Portuguese speakers, with knee pain in the previous six months and a diagnosis of knee osteoarthritis. We used exploratory factor analysis (EFA) followed by confirmatory factor analysis (CFA) with implementation of a polychoric matrix and the robust diagonally weighted least squares (RDWLS) extraction method. The adequacy of the model was assessed using the following fit indices: root mean square error of approximation (RMSEA), comparative fit index (CFI), Tucker-Lewis index (TLI), standardized root mean square residual (SRMR) and chi-square/degree of freedom (DF).

RESULTS: 203 patients with knee osteoarthritis were included. The model proposed in this study with two factors, i.e. "pain" (items 1, 2, 3 and 4) and "physical function" (items 10, 11, 16, 17, 18, 19, 21 and 22), showed adequate fit indices in CFA: chi-square/DF $=1.30 ; \mathrm{CFI}=0.976 ; \mathrm{TLI}=0.970 ; \mathrm{RMSEA}=0.039$; and SRMR $=0.070$. The factorial loads ranged from 0.68 to 0.76 for the "pain" domain and 0.44 to 0.62 for the "physical function" domain.

CONCLUSION: The Brazilian version of WOMAC with two domains, i.e. "pain" (four items) and "physical function" (eight items), presents the best structure.

\section{INTRODUCTION}

The Western Ontario and McMaster Universities Osteoarthritis Index (WOMAC) is a patientbased self-report instrument that was created and validated in English in 1988, to measure pain, joint stiffness and physical function among patients with hip or knee osteoarthritis. This initial study involved face, content and construct validity, reliability and responsiveness. ${ }^{1}$

Since its creation, WOMAC has been translated, adapted and validated for use in several other languages, such as German, Spanish, Japanese, Swedish and Arabic. ${ }^{2}$ There is also a Brazilian Portuguese language version but, curiously, the study in which the translation, cross-cultural adaptation and validation were performed was not published in a peer-reviewed scientific journal (it was a master's dissertation). However, adequate values for reliability and construct validity were identified. ${ }^{3}$

In that version of WOMAC in Brazilian Portuguese, the structural validity of the questionnaire was not ascertained. In other languages, some studies have investigated the structural validity of WOMAC by means of factor and Rasch analysis. According to a systematic review published in $2015,{ }^{2}$ factor analysis was conducted in five studies and variation from three to seven in the number of WOMAC domains was observed. Bilbao et al. ${ }^{4}$ highlighted that the Spanish structure of WOMAC with three domains and 24 items was inadequate and proposed a short version with two domains and 11 items, through using confirmatory factor analysis. Rothenfluh et al. ${ }^{5}$ used Rasch analysis and proposed a German version of WOMAC with one domain and 12 items. 
Also using Rasch analysis, Davis et al. ${ }^{6}$ proposed a new English version of WOMAC with two domains and 17 items.

Thus, considering the different investigations conducted and the different scientific conclusions reached regarding the structure of WOMAC, our study was justified by the need to identify whether the original structure of WOMAC, as used in its translation into the Brazilian Portuguese language, is adequate.

\section{OBJECTIVE}

The aim of this study was to assess the structural validity of the Brazilian version of WOMAC, among patients with knee osteoarthritis.

\section{METHODS}

\section{Ethical aspects}

This study was based on secondary analysis on data from previous studies. ${ }^{7,8}$ It included participants who had been excluded from these previous studies, but who presented eligibility for the present study. The study procedures were approved by our institution's research ethics committee, under opinion report number 24568013.0.0000.5511, on February 10, 2014. The subjects' participation in the previous studies had been authorized and validated through their signing of an official document.

\section{Sample}

The sample size calculation for the present study was based on the recommendations of the COnsensus-based Standards for the selection of health Measurement INstruments (COSMIN), i.e. seven patients for each questionnaire item, thus resulting in a minimum of 168 patients for WOMAC. ${ }^{9}$

All participants in this study were recruited from the waiting lists of two physiotherapy clinics and five primary healthcare units in the city of São Paulo (SP), Brazil. The study included males and females aged 40 to 80 years who were native Brazilian Portuguese speakers, with knee pain in the previous six months and a diagnosis of knee osteoarthritis based on the criteria established by the American College of Rheumatology, with radiographic confirmation of the diagnosis. ${ }^{10}$ These diagnoses of knee osteoarthritis were made through examination and the written opinion of a physician who was a specialist in rheumatic diseases. The exclusion criteria comprised a history of knee trauma, cognitive impairment, several psychiatric conditions (delirium, neurocognitive disorders or schizophrenia), neurological disorder (sensory or motor) or other disorders of the lower limbs that compromised their functioning.

\section{WOMAC}

This study used the WOMAC version with Likert scale responses. As in the study conducted by Fernandes, ${ }^{3}$ the Brazilian Portuguese version has three domains, namely: "pain" domain with five items (items 1, 2, 3, 4 and 5); "stiffness" domain with two items (items 6 and 7); and "physical function" domain with 17 items (items 8, 9, 10, $11,12,13,14,15,16,17,18,19,20,21,22,23$ and 24). For each item, there are five possible answers, ranging from 0 to 4 . The score for each domain is calculated as the simple sum of the items answered: in the "pain domain", the score ranges from 0 to 20 ; in the "stiffness" domain, the score ranges from 0 to 8 ; and in the "physical function" domain, the score ranges from 0 to 68 points.

In the original version, the reliability found was considered adequate, with an intraclass coefficient correlation ranging from 0.73 to 0.97 . Regarding the construct validity, there was an adequate correlation between the WOMAC domains and the Visual Analogue Scale, Health Assessment Questionnaire and Lequesne Algofunctional Index, with correlation magnitudes ranging from 0.425 to 0.935 .

\section{Statistical analysis}

To identify the best WOMAC structure for its version in the Brazilian Portuguese language, exploratory factor analysis (EFA) was initially used, with implementation of a polychoric matrix and the robust diagonally weighted least squares (RDWLS) extraction method, since the response possibilities for each item of WOMAC are ordinal values. ${ }^{11,12}$ The number of factors to be retained was identified and defined by means of parallel analysis with random permutation of the observed data. The rotation used was robust promin. ${ }^{13,14}$ Data processing was performed using the free software FACTOR (Universitat Rovira i Virgili, Tarragona, Spain). The adequacy of the model was assessed using Kaiser-Meyer-Olkin (KMO) and Bartlett's test of sphericity. KMO values above 0.70 and significant P-values in Bartlett's test were considered adequate. ${ }^{15,16}$

Confirmatory factor analysis (CFA) was performed using the R Studio software (Boston, MA, USA) via its lavaan and semPlot packages. The WOMAC questionnaire is scored on a Likert scale (ordinal data). Thus, the CFA was performed with implementation of a polychoric matrix and the RDWLS extraction method, which is more suitable for ordinal variables than the maximum likelihood method. ${ }^{11,17}$ The model fit was assessed using the following indices: root mean square error of approximation (RMSEA) with $90 \%$ confidence interval (CI); comparative fit index (CFI); Tucker-Lewis index (TLI); standardized root mean square residual (SRMR); and chi-square/degree of freedom (DF).

In the present study, values greater than 0.90 were considered adequate according to the CFI and TLI, and values less than 0.08 were considered adequate according to the RMSEA and SRMR. Values below 3.00 were considered adequate in interpreting the chi-square/DF data. ${ }^{18,19}$ In CFA, factorial loads greater than or equal to 0.40 were considered adequate for the domain. The Akaike information criterion (AIC) and Bayesian information criterion 
(BIC) were used to compare the models, and the lowest value was considered to be the most appropriate.

\section{RESULTS}

This study included 203 patients with knee osteoarthritis. The personal and clinical characteristics are described in Table 1. In our sample, most of the patients were elderly, female and overweight.

The EFA was carried out to explore and identify the structure of the Brazilian version of WOMAC. By means of parallel analysis, two factors were identified: the "pain" domain (items 1 to 5) and the "physical function" domain (items 6 to 24). This WOMAC structure was called Model 1. The EFA with parallel analysis presented suitable fit indices: $\mathrm{KMO}=0.75$ and Bartlett's test with $\mathrm{P}<0.001$. Figure 1 presents the scree plot of this parallel analysis with the two factors defined.

From this parallel analysis, we defined Model 2 using the following procedures: items with factorial loads less than 0.50 were excluded (items 6, 7, 8, 9, 12, 13, 14, 15, 20, 23 and 24); item 5 was also excluded because it was originally created for the "pain" domain, but the factorial load of this item allocated it to the "physical function" domain (cross-loading). Therefore, Model 2 was composed of two factors: "pain" (items 1, 2, 3 and 4) and "physical function" (items 10, 11, 16, 17, 18, 19, 21 and 22).

Next, CFA was performed on Model 1 and Model 2. In addition, CFA was performed on the original version conducted by Fernandes $^{3}$ (Model 3) and on the short-form WOMAC proposed by Bilbao et al. ${ }^{4}$ (Model 4). Among these structural models for WOMAC tested here, Model 2 presented the most adequate values for the fit indices and the lowest values of AIC and BIC, as shown in Table 2. The factorial loads for WOMAC with the structure of Model 2 are presented in Figure 2, ranging from 0.68 to 0.76 for the "pain" domain and from 0.44 to 0.62 for the "physical function" domain. The version of WOMAC with the most suitable structure is shown in Appendix 1.

Table 1. Characteristics of the study sample $(n=203)$

\begin{tabular}{lc} 
Characteristics & Mean (standard deviation) or $\mathbf{n}(\%)$ \\
\hline Age (years) & $66.89(4.56)$ \\
\hline $\begin{array}{l}\text { Gender } \\
\quad \text { Male }\end{array}$ & $18(8.9 \%)$ \\
$\quad$ Female & $185(91.1 \%)$ \\
\hline Weight $(\mathbf{k g})$ & $71.53(4.97)$ \\
\hline Height $(\mathbf{m})$ & $1.65(0.06)$ \\
\hline Body mass index $\left(\mathbf{k g} / \mathbf{m}^{2}\right)$ & $26.23(2.75)$ \\
Numerical pain rating (0-10) & $6.57(1.10)$ \\
WOMAC (2 domains, 12 items) & \\
$\quad$ Pain (0-16) & $11.95(1.81)$ \\
$\quad$ Physical function (0-32) & $24.18(2.77)$ \\
\hline
\end{tabular}

WOMAC = Western Ontario and McMaster Universities Osteoarthritis Index.

\section{DISCUSSION}

Our study revealed that the most suitable structure for WOMAC in Brazilian Portuguese has two domains: four items in the pain domain (items 1, 2, 3 and 4) and eight items in the physical function domain (items 10,11, 16, 17, 18, 19, 21 and 22). The structural validity of WOMAC has been tested in several studies. According to a systematic review conducted by Gandek, ${ }^{2}$ EFA was carried out on four studies, ${ }^{20-23}$ and the number of factors (domains) retained for the English and Chinese versions of WOMAC were $3,4,5$ and 7 . This number of domains was higher than the two found in the present study.

We emphasize that our study used parallel analysis as the factor retention method, whereas the abovementioned EFA used other methods for such purposes. Currently, parallel analysis is considered to be a more adequate and robust method for identifying the number of factors in a questionnaire. ${ }^{24,25}$ Another positive point of the present study is that we implemented factor analysis based on a polychoric matrix and we used RDWLS as an extraction method. These implementations are appropriate and should be used for ordinal categorical data, as in the case of the Likert scale $(0,1,2,3$ and 4$))^{11,12}$

In addition to the studies cited in the systematic review conducted by Gandek, ${ }^{2}$ the original WOMAC structure with three domains and 24 items has been rejected by other authors who used the Rasch analysis. Davis et al. ${ }^{6}$ included patients before and after total hip or knee arthroplasty and identified two domains as the best WOMAC structure in English: pain (three items) and physical function (14 items). Another study that investigated the structure of the German version of WOMAC included patients with femoroacetabular impingement and hip osteoarthritis. These authors established a one-dimensional structure for WOMAC with 12 items as the appropriate option. ${ }^{5}$

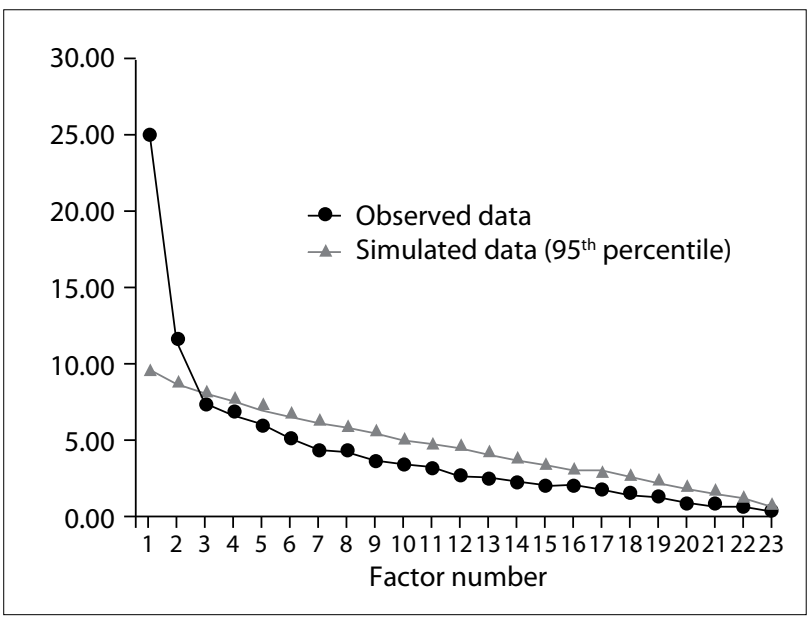

Figure 1. Scree plot from parallel analysis. 
Table 2. Confirmatory factor analysis on the four structures of the Western Ontario and McMaster Universities Osteoarthritis Index tested in this study

$\begin{array}{lccccccccc}\text { Models } & \text { Chi-square } & \text { DF } & \text { Chi-square/DF } & \text { CFI } & \text { TLI } & \text { RMSEA (90\% CI) } & \text { SRMR } & \text { AIC } & \text { BIC } \\ \text { Model 1 } & 415.205 & 249 & 1.66 & 0.869 & 0.854 & 0.057(0.048-0.067) & 0.093 & 8381.240 & 8543.587 \\ \text { Model 2 } & 69.288 & 53 & 1.30 & 0.976 & 0.970 & 0.039(0.000-0.063) & 0.070 & 3807.299 & 3883.503 \\ \text { Model 3 } & 413.064 & 229 & 1.80 & 0.848 & 0.832 & 0.063(0.053-0.073) & 0.097 & 8353.780 & 8522.754 \\ \text { Model 4 } & 113.145 & 43 & 2.63 & 0.850 & 0.809 & 0.090(0.070-0.110) & 0.098 & 4175.547 & 4258.377\end{array}$

$\mathrm{DF}=$ degree of freedom; $\mathrm{CFI}=$ comparative fit index; TLI = Tucker-Lewis index; RMSEA = root mean square error of approximation; $\mathrm{Cl}=$ confidence interval; SRMR: standardized root mean square residual; AIC = Akaike information criterion; BIC: Bayesian information criterion.

Model 1: two domains, four items in the pain domain and 20 items in the physical function domain; Model 2: two domains, four items in the pain domain and eight items in the physical function domain; Model 3: original version proposed by Fernandes, five items in the pain domain, two items in the stiffness domain and 17 items in the physical function domain; Model 4: version proposed by Bilbao et al., three items in the pain domain and eight items in the physical function domain.

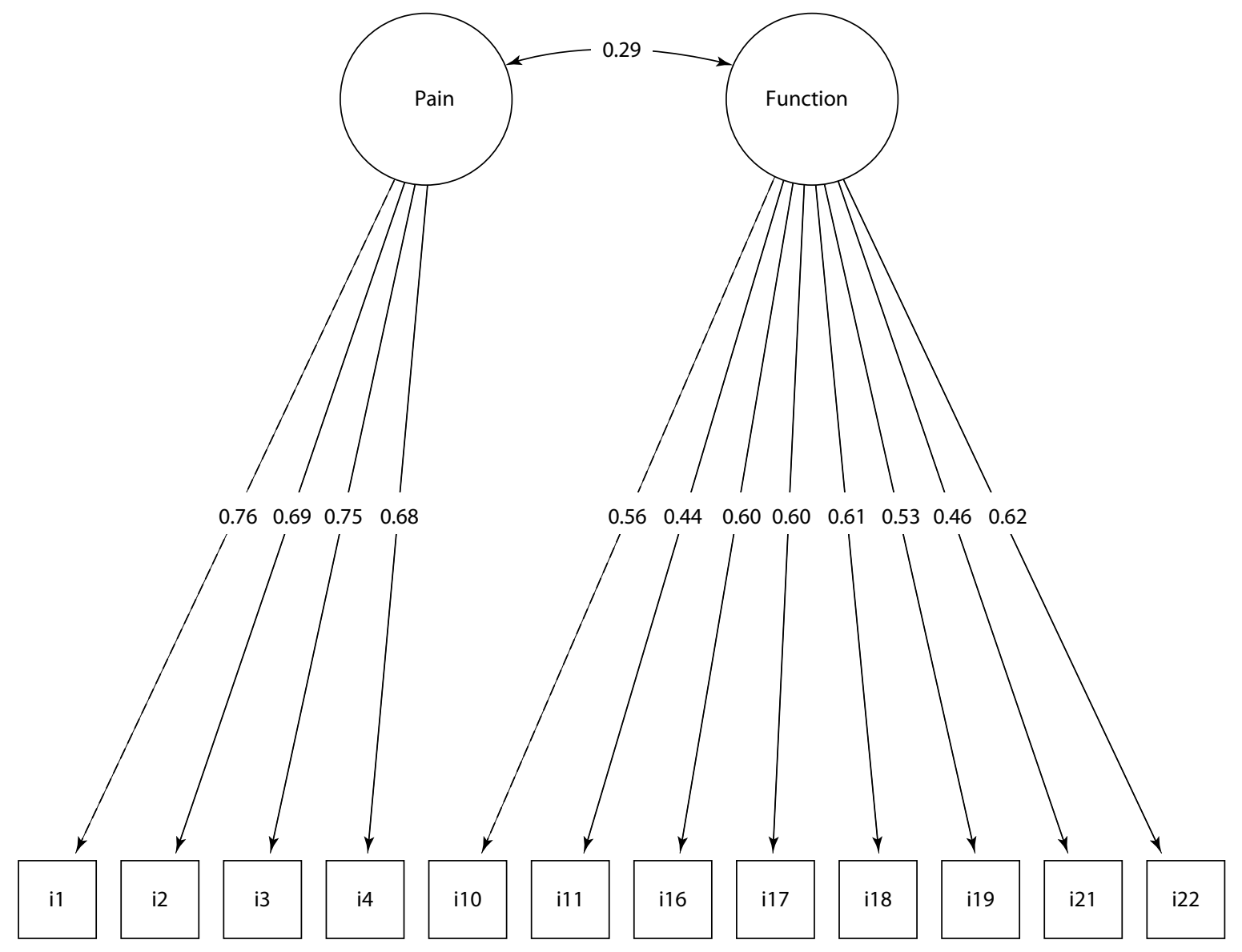

Figure 2. Domains and factorial loads of items of the Western Ontario and McMaster Universities Osteoarthritis Index (WOMAC).

Bilbao et al. ${ }^{4}$ included patients with hip osteoarthritis and identified a Spanish WOMAC structure with two domains: pain (three items) and physical function (eight items). According to our results, the structure of WOMAC in Brazilian Portuguese also presents the same two domains. However, we identified one more item in the pain domain (item 3), and we also identified eight items in the physical function domain; but of these eight items, only three are in agreement with the aforementioned study (items 10, 16 and 22). In addition, we performed a comparison between different structures for WOMAC; the structure that we proposed presented better fit indices for the model compared with the original structure of WOMAC (three domains; 24 items) and the structure proposed by Bilbao et al. ${ }^{4}$

Our data show that the original version of WOMAC, traditionally used in Brazil by researchers and clinical professionals, 
should be replaced by the short version presented here. WOMAC is the questionnaire most used to track and identify the signs and symptoms of patients with osteoarthritis. It is an adequate tool for following the clinical changes among patients in the light of therapeutic interventions. We firmly believe that our results, based on factor analysis and model comparison, should serve as a basis for a new understanding of WOMAC and its "pain" and "physical function" domains.

Our study has some limitations. Only structural validity was considered in the present study. Our sample consisted of patients with knee osteoarthritis, and hip osteoarthritis patients were not included. Other important psychometric properties need to be evaluated through future studies, such as reliability and construct validity (correlation with other instruments and questionnaires that measure pain and function). ${ }^{9}$

\section{CONCLUSION}

The Brazilian version of WOMAC with two domains, i.e. "pain" (four items) and "physical function" (eight items), presents the best structure.

\section{REFERENCES}

1. Bellamy N, Buchanan WW, Goldsmith CH, Campbell J, Stitt LW. Validation study of WOMAC: A health status instrument for measuring clinically important patient relevant outcomes to antirheumatic drug therapy in patients with osteoarthritis of the hip or knee. J Rheumatol. 1988;15(12):1833-40. PMID: 3068365.

2. Gandek B. Measurement properties of the Western Ontario and McMaster Universities Osteoarthritis Index: a systematic review. Arthritis Care Res (Hoboken). 2015;67(2):216-29. PMID: 25048451; doi: 10.1002/ acr.22415.

3. Fernandes MI. Tradução e Validação do Questionário de Qualidade de Vida Específico Para Osteoartrose WOMAC (Western Ontario And McMaster Universities) para a Língua Portuguesa [dissertation]. São Paulo: Universidade Federal de São Paulo; 2002. Available from: http:// repositorio.unifesp.br/handle/11600/19401. Accessed in 2020 (Mar 4).

4. Bilbao A, Quintana JM, Escobar A, Las Hayas C, Orive M. Validation of a proposed WOMAC short form for patients with hip osteoarthritis. Health Qual Life Outcomes. 2011;9:75. PMID: 21936886; doi: 10.1186/14777525-9-75.

5. Rothenfluh DA, Reedwisch D, Müller U, et al. Construct validity of a 12-item WOMAC for assessment of femoro-acetabular impingement and osteoarthritis of the hip. Osteoarthritis Cartilage. 2008;16(9):1032-8. PMID: 18602281; doi: 10.1016/j.joca.2008.02.006.

6. Davis AM, Badley EM, Beaton DE, et al. Rasch analysis of the Western Ontario McMaster (WOMAC) Osteoarthritis Index: Results from community and arthroplasty samples. J Clin Epidemiol. 2003;56(11):107683. PMID: 14614998; doi: 10.1016/s0895-4356(03)00179-3.
7. de Paula Gomes CAF, Leal-Junior ECP, Dibai-Filho AV, et al. Incorporation of photobiomodulation therapy into a therapeutic exercise program for knee osteoarthritis: A placebo-controlled, randomized, clinical trial. Lasers Surg Med. 2018;50(8):819-28. PMID: 29733117; doi: 10.1002/ Ism.22939.

8. Gomes CAFP, Dibai-Filho AV, Biasotto-Gonzalez DA, Politti F, Camillo de Carvalho PT. Association of Pain Catastrophizing With Static Balance, Mobility, or Functional Capacity in Patients With Knee Osteoarthritis: A Blind Cross-sectional Study. J Manipulative Physiol Ther. 2018;41 (1):42-6. PMID: 29249415; doi: 10.1016/j.jmpt.2017.08.002.

9. Prinsen CAC, Mokkink LB, Bouter LM, et al. COSMIN guideline for systematic reviews of patient-reported outcome measures. Qual Life Res. 2018;27(5):1147-57. PMID: 29435801; doi: 10.1007/s11136-018$1798-3$.

10. Kellgren JH, Lawrence JS. Radiological assessment of osteo-arthrosis. Ann Rheum Dis. 1957;16(4):494-502. PMID: 13498604; doi: 10.1136/ ard.16.4.494.

11. Li CH. Confirmatory factor analysis with ordinal data: Comparing robust maximum likelihood and diagonally weighted least squares. Behav Res Methods. 2016;48(3):936-49. PMID: 26174714; doi: 10.3758/s13428-0150619-7.

12. DiStefano C, Morgan GB. A Comparison of Diagonal Weighted Least Squares Robust Estimation Techniques for Ordinal Data. Structural Equation Modeling. 2014;21(3):425-38. doi: 10.1080/10705511.2014.915373.

13. Timmerman ME, Lorenzo-Seva U. Dimensionality assessment of ordered polytomous items with parallel analysis. Psychol Methods. 2011;16(2):209-20. PMID: 21500916; doi: 10.1037/a0023353.

14. Lorenzo-Seva U, Ferrando PJ. Robust Promin: a method for diagonally weighted factor rotation. Lib Rev Peru Psicol. 2019;25(1):99-106. doi: 10.24265/liberabit.2019.v25n1.08.

15. Hutcheson G, Sofroniou N. The Multivariate Social Scientist. The Multivariate Social Scientist. London: SAGE Publications; 1999.

16. Tabachnick BG, Fidell LS. Using multivariate statistics. $5^{\text {th }}$ ed. Boston: Allyn \& Bacon; 2007.

17. Ullman JB. Structural equation modeling: reviewing the basics and moving forward. J Pers Assess. 2006;87(1):35-50. PMID: 16856785; doi: 10.1207/s15327752jpa8701_03.

18. Schermelleh-Engel $K$, Moosbrugger $H$, Müller $H$. Evaluating the Fit of Structural Equation Models: Tests of Significance and Descriptive Goodness-of-Fit Measures. MPR-online. 2003;8(2):23-74. Available from: http://www.stats.ox.ac.uk/ snijders/mpr_Schermelleh.pdf. Accessed in 2020 (Mar 4).

19. Brown TA. Confirmatory factor analysis for applied research. $1^{\text {st }} \mathrm{ed}$. New York: Guilford Press; 2006. ISBN: 9781593852740.

20. Xie F, Li SC, Goeree R, et al. Validation of Chinese Western Ontario and McMaster Universities Osteoarthritis Index (WOMAC) in patients scheduled for total knee replacement. Qual Life Res. 2008;17(4):595601. PMID: 18415706; doi: 10.1007/s11136-008-9340-7. 
21. Kennedy D, Stratford PW, Pagura SMC, et al. Exploring the Factorial Validity and Clinical Interpretability of the Western Ontario and McMaster Universities Osteoarthritis Index (WOMAC). Physiother Can. 2003;55(03):160. doi: 10.2310/6640.2003.2240.

22. Stratford PW, Kennedy DM. Does parallel item content on WOMAC's pain and function subscales limit its ability to detect change in functional status? BMC Musculoskelet Disord. 2004;5:17. PMID: 15189563; doi: 10.1186/1471-2474-5-17

23. Stratford PW, Dogra M, Woodhouse L, Kennedy DM, Spadoni GF. Validating self-report measures of pain and function in patients undergoing hip or knee arthroplasty. Physiother Can. 2009;61 (4):18994; discussion 195-6. PMID: 20808479; doi: 10.3138/physio.61.4.189.

24. Wood ND, Akloubou Gnonhosou DC, Bowling J. Combining Parallel and Exploratory Factor Analysis in Identifying Relationship Scales in Secondary Data. Marriage Fam Rev. 2015;51 (5):385-95. PMID: 2649493; doi: 10.1080/01494929.2015.1059785.

25. Hayton JC, Allen DG, Scarpello V. Factor Retention Decisions in Exploratory Factor Analysis: a Tutorial on Parallel Analysis. Organizational Research Methods. 2016;7(2):191-205. doi: 10.1177/1094428104263675.

Authors' contributions: Ferreira CSB: data curation, formal analysis, methodology and writing-original draft; Dibai-Filho AV: conceptualization, data curation, formal analysis, methodology and writing-review and editing; Almeida DOS: investigation, methodology and writing-original draft; Bassi-Dibai D: conceptualization, formal analysis, methodology and writing-review and editing; Barreto FS: investigation, methodology and writing-original draft; Oliveira AR: conceptualization, formal analysis, methodology and writing-review and editing; and Fidelis-de-Paula-Gomes CA: conceptualization, data curation, formal analysis, methodology, project administration and writing-review and editing. All authors approved the final version of the manuscript for publication

Sources of funding: None

Conflict of interest: None

Date of first submission: March 4, 2020

Last received: June 7, 2020

Accepted: June 26, 2020

\section{Address for correspondence:}

Cid André Fidelis-de-Paula-Gomes

Programa de Pós-graduação em Ciências da Reabilitação, Universidade Nove de Julho (UNINOVE)

R. Vergueiro, 235/249 - 2- subsolo

Liberdade — São Paulo (SP) — Brasil

CEP 01504-001

Tel. (+55 11) 3385-9241

E-mail: cid.andre@gmail.com 
Appendix 1. Short version of Western Ontario and McMaster Universities Osteoarthritis Index (WOMAC) for the Brazilian population.

\section{DOR}

As questões abaixo se referem à intensidade de dor que você geralmente sente devido à artrose. Para cada situação, por favor, marque a intensidade da dor sentida nas últimas 72 horas (marcar suas respostas com um " $\mathrm{X}$ ").

Qual a intensidade de dor que você apresentou...

1 - Caminhando em um lugar plano?

\begin{tabular}{|c|c|c|c|c|}
\hline Nenhuma $\square$ & Pouca $\square$ & Moderada $\square$ & Intensa $\square$ & Muito Intensa $\square$ \\
\hline \multicolumn{5}{|c|}{2 - Subindo ou descendo escadas? } \\
\hline Nenhuma $\square$ & Pouca $\square$ & Moderada $\square$ & Intensa $\square$ & Muito Intensa $\square$ \\
\hline \multicolumn{5}{|c|}{3 - Deitado(a) na cama à noite? } \\
\hline Nenhuma $\square$ & Pouca $\square$ & Moderada $\square$ & Intensa $\square$ & Muito Intensa $\square$ \\
\hline \multicolumn{5}{|c|}{4 - Sentando-se ou deitando-se? } \\
\hline Nenhuma $\square$ & Pouca $\square$ & Moderada $\square$ & Intensa $\square$ & Muito Intensa $\square$ \\
\hline
\end{tabular}

\section{FUNÇÃo}

As questões abaixo se referem à sua atividade física, isso quer dizer sua capacidade para movimentar-se e para cuidar-se. Para cada uma das atividades abaixo, por favor, marque o grau de dificuldade que você apresentou para realizá-las nas últimas 72 horas devido à artrose (favor marcar suas respostas com um " $X$ ").

Qual o grau de dificuldade que você apresentou ao...

10 - Levantar-se estando sentado(a)?

Nenhuma $\square \quad$ Pouca $\square$

11 - Ficar em pé?

Nenhuma $\square$

Pouca $\square$

Moderada $\square$

Intensa $\square$

Muito Intensa $\square$

Moderada $\square$

Intensa $\square$

Muito Intensa $\square$

16 - Colocar as meias?

Pouca $\square$

Moderada $\square$

Intensa $\square$

Muito Intensa $\square$

17 - Levantar-se da cama?

Pouca $\square$

Moderada $\square$

Intensa $\square$

Muito Intensa $\square$

18 - Tirar as meias?

Nenhuma $\square$

Pouca $\square$

Moderada $\square$

Intensa $\square$

Muito Intensa $\square$

19 - Ficar deitado(a) na cama?

Pouca $\square$

Moderada $\square$

Intensa

Muito Intensa

21 - Sentar-se?

Nenhuma $\square$

Pouca $\square$

Moderada $\square$

Intensa $\square$

Muito Intensa $\square$

22 - Sentar-se ou levantar-se do vaso sanitário?

Nenhuma $\square$

Pouca $\square$

Moderada $\square$

Intensa

Muito Intensa $\square$ 